\title{
Unusually localised cutaneous multifocal squamous cell carcinoma
}

\author{
Radhika Varma, N. Asokan, A. Sarin, Nadiya Rahman \\ Department of Dermatology Venereology and Leprosy, Government Medical College, Thrissur, India
}

Corresponding author: Dr. Radhika Varma, E-mail: drradhikavarma@gmail.com

\begin{abstract}
Skin cancer is predominantly a disease of the elderly and accounts for about $53 \%$ of all deaths in those more than 65 years old in Whites. Although it classically presents as a solitary painless nonhealing ulcer, varied presentations as plaques, nodules and warty lesions are not rare. Herein we report a case of an otherwise healthy elderly female with cutaneous squamous cell carcinoma (SCC) which presented as multiple, slowly enlarging painless non-ulcerated skin nodules localized to the anteromedial aspect of right leg. We wish to highlight that uncharacteristic presentations of cutaneous SCC may occur even in immunocompetent individuals.
\end{abstract}

Key words: Skin nodules; Carcinoma; Multifocal carcinoma

\section{INTRODUCTION}

Squamous cell carcinoma [SCC] is the second most common cutaneous neoplasm and accounts for about $20 \%$ of all skin malignancies [1].Cutaneous SCC is a malignant tumor of keratinizing epidermal cells. Clinical behavior of SCC can vary from indolent to aggressive metastatic types [2]. Multiple cutaneous type is a rare presentation of SCC and arises either as a de novo multicentric tumour or following spread from primary SCC elsewhere via shelving, conduit spread, local lymphatic metastasis or disseminated metastasis [3]. Herein, we report a patient with long standing multiple skin nodules localized to the right leg which were later diagnosed as SCC.

\section{CASE REPORT}

A 75 year old woman was seen in dermatology OPD for multiple, firm, asymptomatic swellings on right shin, slowly enlarging over the past 20 years. She had no previous scars or skin diseases at that site. Examination revealed fourteen erythematous and skin coloured nodules of sizes ranging from $2 \times 1 \mathrm{~cm}$ to $4 \times 3 \mathrm{~cm}$ on upper half of anterior and medial aspects of right leg.
Some nodules had central keratin filled craters and the surrounding skin was mildly erythematous (Fig. 1). She had mild ichthyosis of both legs. We considered dermatofibroma, nodular basal cell carcinoma and indolent cutaneous lymphomas as differential diagnoses. Haemogram was normal except for an erythrocyte sedimentation rate of $130 \mathrm{~mm}$ in first hour. Chest $\mathrm{x}$-ray was normal. Intradermal tuberculin test using $0.1 \mathrm{ml}$ of purified protein derivative was negative. Ultrasonogram of abdomen showed mild enlargement of right inguinal lymph nodes and fine needle aspiration cytology (FNAC) from these nodes did not show any abnormal cells. Serum was negative for HBsAg, HIV and Hepatitis A and C viruses. FNAC from the skin nodules showed cells of SCC (Fig. 2).

She underwent wide excision of tumour nodules followed by skin grafting (Fig. 3). Histopathology of the tissue showed atypical squamous epithelium in nests, invading adjacent stroma (Fig. 4). The squamous cells had large, vesicular and hyperchromatic nuclei, prominent nucleoli and anisonucleosis with occasional individual cell keratinisation. The stroma showed dense infiltration by lympho-plasma cells. Keratin pearls and mitoses were seen suggestive of a moderately

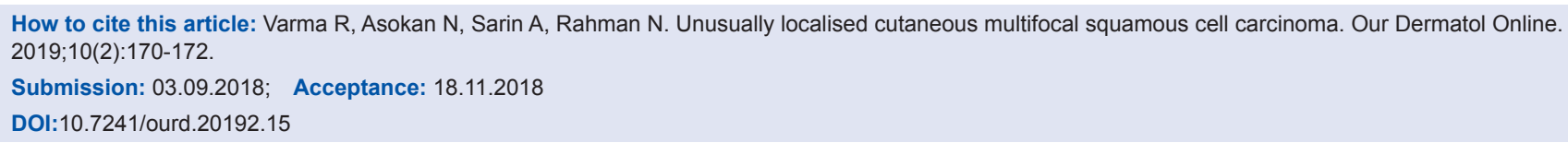




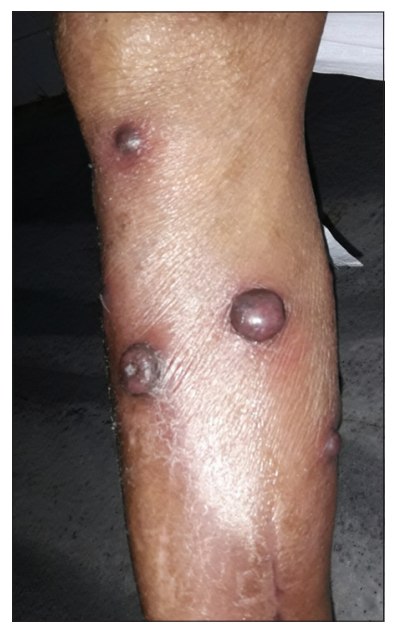

Figure 1: Erythematous nodules on leg showing central crater with adherent scaling. Surrounding skin shows erythema and ichthyosis.

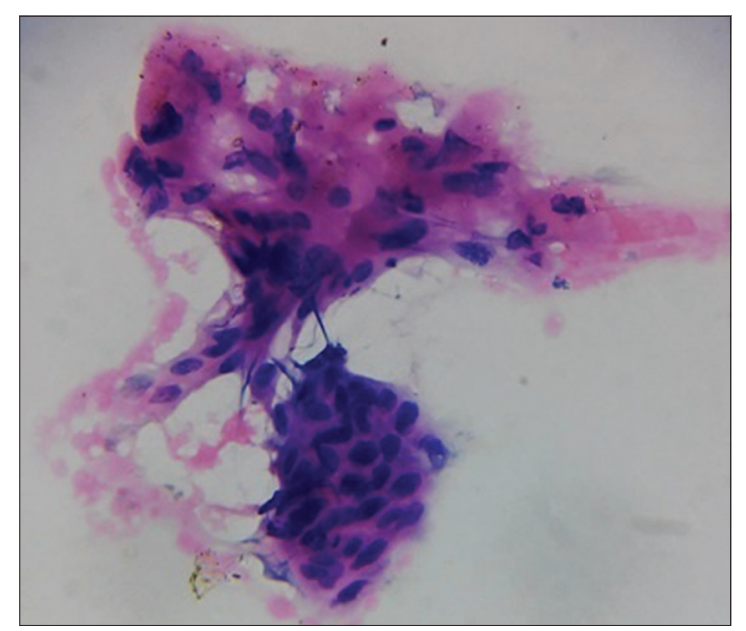

Figure 2: FNAC smear showing atypical squamous cells in cluster. Individual cells have moderate eosinophilic cytoplasm and central pleomorphic and hyperchromatic nucleus. H\&E Stain. X 400 magnification.

differentiated squamous cell carcinoma. The resected skin margins were free of neoplastic infiltration. Post operative period was uneventful and follow up of one and half years showed no recurrence.

\section{DISCUSSION}

SCC arises more commonly on sun exposed areas of skin like head, neck and arms [3]. Chronic ultraviolet radiation, human papiloma virus (HPV) infection and immunosuppression play a major role in its pathogenesis. Other risk factors for SCC include exposure to oral psoralens, arsenic, hydrocarbons, coal tar products, solid organ transplantation and diseases like chronic lymphocytic leukemia [1,3]. Patients with genetic diseases like xeroderma pigmentosum, epidermodysplasia verruciformis and

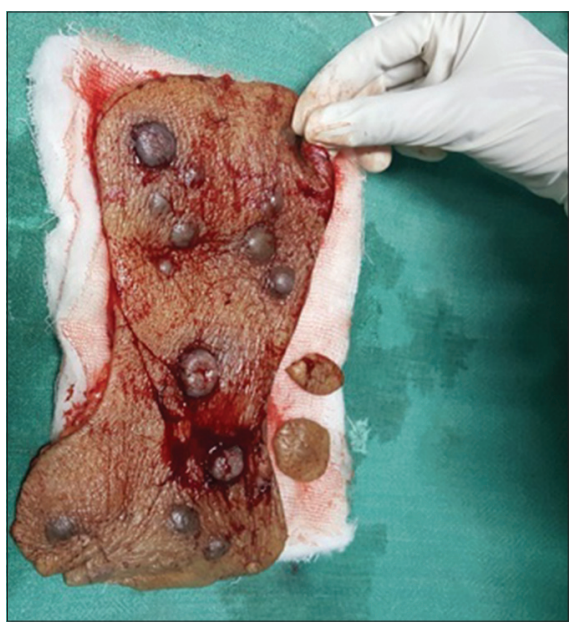

Figure 3: Wide excision specimen of skin of right leg showing fourteen discrete nodules.

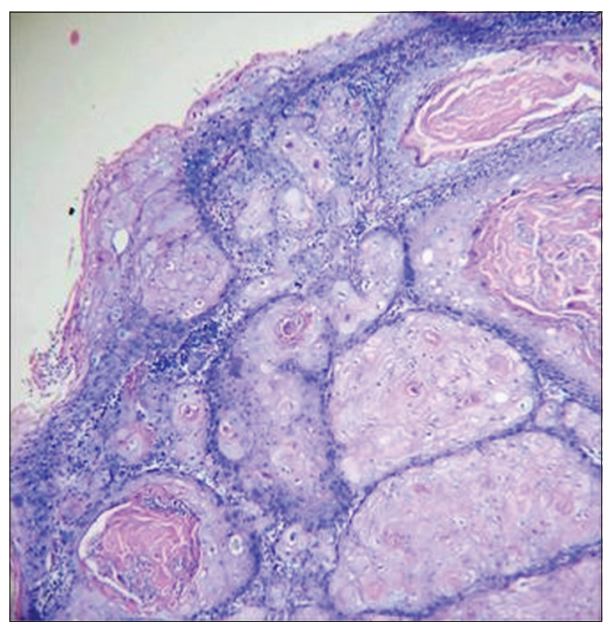

Figure 4: Nests of atypical squamous cells from epidermis invading stroma in masses. Dermis contain dense infiltrate of lymphocytes and plasma cells. H\&E stain, $x 100$ magnification.

oculocutaneous albinism have a higher incidence of this neoplasm $[3,4]$. SCC also arise on long standing cases of lupus vulgaris, discoid lupus erythematosus, herpes zoster and chronic stasis dermatitis $[1,3,4]$. Fair skin,older age, blue eyes and red-blonde hair are other factors which correlate with occurrence of SCC [1]. Individuals with human immunodeficiency virus infection have a substantially increased risk for developing aggressive tumor with high recurrence rates and increased metastasis.

Multiple cutaneous SCC has been reported in patients with psoriasis and vitiligo treated with oral psoralens and UV radiation, with HPV infections, interferon $\gamma$ receptor 2 deficiency and following cutaneous metastasis from vulvar SCC [3-5]. It has also been reported in patients receiving treatment with ustekinumab, voriconazole and sorafenib [6-8]. 
Cutaneous metastases, occur only in $0.7 \%$ to $9 \%$ of all malignancies and usually develop following the diagnosis of a primary tumour [3].In women, the most common sources of cutaneous metastases are carcinomas of breast, colon and ovary. Presence of a metastatic cancer without a known primary site of origin despite a standardized diagnostic workup is termed as carcinoma of unknown primary site (CUPS) [9]. CUPS usually presents with rapidly developing widespread nodules or tumors which are usually asymptomatic, rarely painful and tender [3]. Diagnosis of such metastasised cutaneous SCC relies on histopathologic evaluation of involved skin wherein tumors may show features of the underlying tumor or may have an anaplastic appearance. An indolent course of almost two decades and localization to one limb rendered a diagnosis of CUPS unlikely in our case. Hence, we consider our patient to have had a primary cutaneous multifocal SCC. We could not identify any reason for the multifocal presentation of the tumour in leg.

Our case is unusual in many ways. Leg is an uncommon site for primary SCC. Localization to one site, a multifocal presentation with absence of ulceration and infiltration of the nodules, absence of regional lymph node metastasis in spite of a long course of are other unusual features in our patient.

Cutaneous SCC varies both in its manifestations and course. Hence, SCC should be considered inthe differential diagnosis of all skin tumours particularly among elderly individuals.

\section{REFERENCES}

1. Syrigos KN, Tzannou I, Katirtzoglou N, Georgiou E. Skin cancer in the elderly. In Vivo. 2005;19:643-52.

2. Cassarino DS, Derienzo DP, Barr RJ. Cutaneous squamous cell carcinoma: A comprehensive clinicopathologic classification: Part One. J Cutan Pathol. 2006;33:191-206.

3. Kaur J, Sharma N, Sharma S. Multiple cutaneous squamous cell carcinomas: Primary carcinomas versus cutaneous metastasis. J Cancer Res Ther. 2012;8:300-2.

4. Üstüner P, Dilek N, Güçer H. Genital squamous cell carcinoma presenting with multicentric ulcers: an unusual manifestation of skin malignancy. Indian Dermatol Venereol Leprol 2012;78:195-7.

5. Toyoda H, Ido M, Nakanishi K, Nakano T, Kamiya H, Matsumine A, et al. Multiple cutaneous squamous cell carcinomas in a patient with interferon gamma receptor 2 (IFN gamma R2) deficiency. J Med Genet. 2010;47:631-4.

6. Young L, Czarnecki D. The rapid onset of multiple squamous cell carcinomas in two patients commenced on ustekinumab as treatment of psoriasis. Australas J Dermatol. 2012;53:57-60.

7. Morice C, Acher A, Soufir N, Michel M, Comoz F, Leroy D, et al. Multifocal aggressive squamous cell carcinomas induced by prolonged voriconazole therapy: a case report. Case Rep Med. 2010;2010:351084.

8. Dubauskas Z, Kunishige J, Prieto VG, Jonasch E, Hwu P, Tannir NM. Cutaneous squamous cell carcinoma and inflammation of actinic keratoses associated with sorafenib. Clin Genitourin Cancer. 2009;7:20-3.

9. Natoli C, Ramazzotti V, Nappi O, Giacomini P, Palmeri S, Salvatore M, et al. Unknown primary tumors. Biochim Biophys Acta - Rev Cancer. 2011;1816:13-24.

Copyright by Radhika Varma,et al. This is an open-access article distributed under the terms of the Creative Commons Attribution License, which permits unrestricted use, distribution, and reproduction in any medium, provided the original author and source are credited. Source of Support: Nil, Conflict of Interest: None declared. 